\title{
ВMJ Global Health Fear and culture: contextualising mental health impact of the 2014-2016 Ebola epidemic in West Africa
}

\author{
Ann O'Leary, ${ }^{1}$ Mohamed F Jalloh, ${ }^{2,3}$ Yuval Neria ${ }^{4,5}$
}

\begin{abstract}
To cite: O'Leary A, Jalloh MF, Neria Y. Fear and culture: contextualising mental health impact of the 2014-2016 Ebola epidemic in West Africa. BMJ Glob Health 2018;3:e000924. doi:10.1136/ bmjgh-2018-000924
\end{abstract}

Handling editor Seya Abimbola

Received 25 April 2018 Accepted 1 May 2018

A) Check for updates

${ }^{1}$ National Center for HIV/AIDS, Viral Hepatitis, STD, and TB Prevention, US Centers for Disease Control and Prevention (CDC), Atlanta, Georgia, USA ${ }^{2}$ Division of Global Health Protection, Centers for Global Health, US Centers for Disease Control and Prevention (CDC), Atlanta, Georgia, USA ${ }^{3}$ Department of Public Health Science, Karolinska Institutet, Stockholm, Sweden ${ }^{4}$ Departments of Psychiatry and Epidemiology, Columbia University Medical Center, New York City, New York, USA ${ }^{5}$ New York State Psychiatric Institute, New York City, New York, USA

Correspondence to Dr Ann 0'Leary; aa00@cdc.gov

\section{INTRODUCTION}

The 2014-2016 Ebola virus disease (Ebola) outbreak in West Africa was the largest, longest, deadliest and most geographically expansive Ebola outbreak since the virus was first discovered in the Democratic Republic of Congo in $1976 .^{1-5}$ Given the unprecedented escalation of the outbreak, the WHO declared it a Public Health Emergency of International Concern in August 2014, ${ }^{6}$ a designation that lasted for 20 months until March 2016. ${ }^{7}$

By the time the epidemic was controlled, it affected 10 countries through locally acquired or imported Ebola cases, resulting in 28652 Ebola cases and 11325 deaths from the disease reported to WHO. ${ }^{8}$ When comparing the 2014-2016 epidemic with the combined 24 previous Ebola outbreaks, there were 12 times more cases, 7 times more deaths and 21 times more patients with Ebola who recovered from and survived the disease.

While Nigeria was more prompt in containing its Ebola outbreak, compared with Sierra Leone, Liberia and Guinea, fear-driven behaviours aggregated adverse consequences on its economy and healthcare utilisationdescribed as fearonomic effect. ${ }^{9}{ }^{10}$ Misinformation caused people to ingest large amounts of salt water (a rumoured curative), breaking quarantine to obtain 'holy water' in Lagos, also rumoured to cure the disease, and casual transmission beliefs caused people to avoid crowded areas-causing many businesses to fail-and health facilities. Ebola survivors and health workers were particularly affected by fear-driven stigmatisation. In Sierra Leone, Ebola survivors reported acute fear and depression when they initially suspected Ebola, as well as experiencing stigmatisation in the community after release from Ebola treatment centres. ${ }^{11}$ In Guinea, some Ebola survivors avoided disclosing their Ebola survivorship status to sexual partners, possibly due to the fear of stigmatisation and rejection. ${ }^{12}$
Few studies have attempted to assess the mental health impact of Ebola on directly affected populations such as Ebola survivors, ${ }^{11-15}$ healthcare workers $^{16-19}$ and other Ebola response staff. $^{20-22}$ In Sierra Leone, one study assessed the nationwide impact of the protracted epidemic. Nearly one-fifth of participants in the Sierra Leone sample reported symptomology that met the definition for probable post-traumatic stress disorder (PTSD) diagnosis if screened in a clinical setting. ${ }^{23}$ In this editorial, we examine recent published research ${ }^{10-122324}$ to provide contexts for better understanding of the mental health impact of Ebola. We discuss the unique role of fear-driven behaviours and the influence of culture on mental health outcomes, possible implications for future outbreak responses, and whether current measurement tools are sufficiently reliable and valid to assess mental health impact during large-scale epidemics.

\section{EFFECTS ATTRIBUTED TO FEAR AND STIGMA}

Fear-related behaviours shaped the recent Ebola epidemic in West Africa. ${ }^{9}$ Defined as 'individual or collective behaviors and actions initiated in response to fear reactions that are triggered by a perceived threat or actual exposure to a potentially traumatizing event', they were implicated in accelerating Ebola transmission, when people avoided seeking healthcare for fear of exposure within the health setting. Describing a different domain of fear-related behaviours, researchers reported damages to the Nigerian economy due to misinformation and fear-induced avoidance, driven by fear of exposure to Ebola, for example on aeroplanes believed to harbour infected individuals, within health centres, inside populated hotels and so on. ${ }^{10}$

Fear-driven stigmatisation adversely affected Ebola survivors. In an August 2014 
national survey in Sierra Leone, the majority (95\%) of all respondents expressed at least one discriminatory attitude towards Ebola survivors. ${ }^{24}$ For instance, $78 \%$ of respondents in that survey said they would not welcome an Ebola survivor back into the community after recovering from the disease. In a national sample of Guineans in August 2014, 17\% incorrectly stated that Ebola survivors may continue to spread the disease through casual contact such as shaking hands or hugging. ${ }^{25}$ Qualitative assessments with Ebola survivors in Sierra Leone and Liberia documented both their own fear of the disease's consequences as well as being feared and stigmatised by some members of their communities. ${ }^{11} 13$ Ebola survivors' experience became even more complicated due to the emergence of sexual transmission of the Ebola virus linked to viral persistence in the semen of male survivors. ${ }^{26-29}$ The possibility of sexual transmission by Ebola survivors created a new dimension of fear. In a survey in Guinea, female sexual partners of Ebola survivors who said they were not informed of their partners' Ebola survivorship status had 20 times greater odds to be unaware of Ebola sexual transmission risks when compared with those who were informed. ${ }^{12}$ Ebola survivors may have feared stigmatisation, and therefore hid their status from sexual partners. A flare-up of Ebola cases in Guinea, following containment of the original outbreak, was linked to sexual transmission by an Ebola survivor. $^{30}$

Similar to Ebola survivors, health workers who took care of patients with Ebola were reportedly stigmatised. Indepth interviews with healthcare workers who survived Ebola revealed repeated discrimination when reintegrating into their communities and health facilities. ${ }^{31} \mathrm{In}$ addition, generalised fear and xenophobic attitudes have been documented outside of the Ebola-affected countries. ${ }^{32}$ For example, a non-representative sample survey of adult Italians found that African immigrants were perceived to be at increased risk for transmitting Ebola. ${ }^{33}$ Taken together, fear-driven stigmatisation may have had adverse mental health impact on Ebola survivors, health workers and their families. Ebola-related stigma may have produced unwanted consequences on containment of the epidemic by discouraging suspected patients from seeking care in order to avoid the label of Ebola. Interventions addressing social stigma during epidemics should be prioritised to address negative mental health impact, and other unwanted consequences on economies and healthcare utilisation.

\section{CULTURAL INFLUENCES AND EFFECTS ON TRADITIONAL PRACTICES}

The 2014-2016 Ebola epidemic vastly disrupted cultural practices and health-seeking behaviours in affected countries in West Africa. Traditional burial rituals involving physical contact when washing corpses were halted in order to reduce transmission risk. ${ }^{34}$ Traditional burials were replaced with medical burials by trained Ebola response teams. However, dissatisfaction with medical burials were documented. Alternatives to traditional burials eventually included allowing families to observe the burial from a safe distance and having a religious leader offer a final prayer on the corpse. ${ }^{35}$ Such alternatives may have helped improve social acceptance of safe medical burials.

Traditional healing practices, usually involving direct physical contact between the healer and the patient, were routinely banned across Sierra Leone in the latter part of the epidemic to mitigate Ebola transmission risks. Traditional healers were encouraged to report all patients to the nearest health facility or to the 1-1-7 national alert line. ${ }^{36}$ It is unclear if the restriction of traditional healing practices had any effects on the population's mental health, especially given that traditional healing is customarily sought for suspected mental health problems.

It is possible that other unrestricted aspects of Sierra Leonean culture may have served as protective factors against mental and psychological distress brought on by the epidemic. A key cultural aspect worth investigating is the population's willingness to openly discuss their experiences during the epidemic. Following the end of the civil conflict in 2002, Sierra Leoneans also used dialogue and story-telling-often in community or group settings-to recount traumatic experiences, which may have been a protective coping mechanism. ${ }^{37}$ Prolonged disruptions in sacred cultural and traditional practices, especially for loved ones who died, may have had severe mental health impact on affected families during the Ebola crisis. However, other pre-existing cultural dynamics may have fostered resilience against expected, adverse mental health outcomes.

Compared with participants in other population-based, mental health studies, those in Sierra Leone showed similar or less severe levels of post-traumatic stress (PTS) symptomatology. ${ }^{23} 38$ Assuming that Ebola touched the lives of most respondents in some way, ${ }^{39}$ prevalence of PTSD seemed lower than expected from the assumed psychological trauma exposure ${ }^{40}$ given the high case fatality of Ebola. ${ }^{34}$ However, consistent with studies conducted in Western societies, ${ }^{41}{ }^{42}$ Sierra Leoneans who had a direct exposure to the epidemic - such as knowing someone who died from Ebola-were more likely to report PTSD symptoms compared with those who did not. ${ }^{23}$ Another study found that PTSD symptoms were significantly associated with lower self-reporting of Ebola prevention behaviours in a regionally representative sample of Sierra Leoneans. ${ }^{43}$ Not only was the likelihood of death extremely high with Ebola, witnessing patients haemorrhage from various parts of their body added another psychological traumatic experience. ${ }^{40}$ Although it has never been assessed, the inability for some families to care for their sick relatives coupled with the inability of some family members to perform traditional and religious burial rituals for their loved ones may have caused psychological distress. 
Following Sierra Leone's horrific civil war (1991-2002), the mental health effects of the conflict on former child soldiers have been systematically documented. ${ }^{44-46}$ Such experiences often involved witnessing brutal killings, rapes and other extreme violence. In one study, levels of depression and anxiety were increased among former child soldiers who returned to communities characterised by social disorder and improved among those who perceived their communities to be accepting of them. ${ }^{44} \mathrm{~A}$ study of adjustment of these former child soldiers showed reductions in PTSD from 32\% to $16 \%$ in 4years even with limited access to care. ${ }^{46}$ Community social support is hypothesised to have contributed to the reduced level of PTSD among former child soldiers.

Prior research has illustrated the potential therapeutic benefit of putting traumatic experiences into words. In one study, college students were randomised to write for 15-20 min a day, for several days, either about past traumatic events about which they had seldom spoken, or about trivial topics. ${ }^{47}$ Those who wrote about traumatic events made half as many visits to the student health centre as those who did not. Organising inchoate emotions and fragmented thoughts resulting from traumatic experiences may have created an organising narrative, which 'cools' the emotional turmoil. ${ }^{48}$

It is possible that Sierra Leoneans may have benefited from cultural dynamics that provided innate social support through their near-constant conversations, which during the Ebola crisis almost certainly included conversations about people's experiences related to the epidemic. Additional research is needed to better understand the effects of cultural attributes on mental health outcomes during large-scale outbreaks. Nonetheless, individuals with Ebola-related experiences-such as knowing someone who died from Ebola or were quarantined-may require additional psychosocial support. ${ }^{23}$ Directly affected populations in affected countries including Ebola survivors, healthcare workers in Ebola treatment centres, ambulance teams and burial workers may also need professional attention including psychosocial support to address the prolonged trauma they witnessed. ${ }^{1314161949}$

\section{MEASURING AND PREVENTING MENTAL HEALTH IMPACT}

Aiming to capture the impact of Ebola experiences and risk perceptions on mental health in Sierra Leone, researchers conducted a population-based study of the epidemic. ${ }^{23}$ In the study, $76 \%$ of all respondents reported one or more PTS symptoms, while $16 \%$ met the clinical cut-off according to screening guidelines for PTSD in the Impact of Events Scale-6 (IES-6) ${ }^{23}$ Interpretation of such findings, however, is made difficult by the limited literature on mental health in Sierra Leone, and lack of other comparable national-level data related to Ebola outbreaks in Africa.

Measuring and responding to the mental health impact of a large-scale epidemic is challenging. ${ }^{40}$ Doing so, in settings where measurement tools have not been validated or used before, is even more challenging. For instance, various screeners used to measure anxiety-depression (Patient Health Questionnaire-4) ${ }^{50} 51$ and PTSD $\left(\right.$ IES-6) ${ }^{38} 52$ in Sierra Leone had not been validated before for use in that setting. Careful efforts were taken by the researchers to ensure accurate translations from English to local languages, especially given that Krio and other local languages are predominantly oral languages. Although PHQ-4 and IES-6 demonstrated acceptable internal reliability and factorial validity in measuring mental outcomes following the Ebola outbreak in Sierra Leone,${ }^{23}$ there is a larger need for reliable validated measurement tools to assess mental health outcomes in West African settings.

\section{CONCLUSION}

Taken together, findings from research projects conducted in the aftermath of the Ebola epidemic have been pointing to a number of challenges that need to be addressed in future large-scale epidemics in low-income/middle-income countries. First, fear-related behaviours and stigmatisation are common, and negatively affect access to care, quality of care and spread of the epidemic. This phenomenon should be addressed from the outset by public and mental health professionals aiming to educate the public via social and digital media, attempting to directly contain fear and panic, and improve access to modern care. Second, local cultures often play a key role in medical response, burial rituals and treatment-seeking for trauma-related disorders such as PTSD, anxiety and depression. Sensitive adaptation of modern psychiatric care to local practices should be an ongoing effort regardless of epidemic breaks, facilitated via partnerships with community and spiritual players. Third, despite early concerns, epidemiological research discussed above highlights impressive levels of emotional resilience throughout Ebola-affected communities. These findings should alleviate early concerns about the scope of the impact of the outbreak and should be accounted in future public health policies.

Nevertheless, the studies also highlight important unmet needs of large populations who suffer from Ebola-related mental health problems, such as PTSD, among people directly affected by the virus, their families, and medical and burial teams. For them culturally sensitive, trauma-focused interventions should be developed and tested before future outbreaks occur, to ensure appropriate and accessible mental health response. Such intervention should integrate gold standard treatments (eg, prolonged exposure treatment), traditional cultural norms, habits, spiritual support and community healing practices. Such integrative efforts may include also assessment methods, training efforts and transmission of public health information via modern communication platforms such as social media. 
Acknowledgements We dedicate this article to the thousands of Sierra Leoneans, Guineans, Liberians, Nigerians and other people around the world whose lives were affected by the unprecedented 2014-2016 Ebola epidemic.

Contributors All authors contributed to the literature review, conceptualisation of the analysis, interpretation of relevant findings and writing substantial parts of the manuscript. All coauthors reviewed and approved the final version of the manuscript.

Funding The authors have not declared a specific grant for this research from any funding agency in the public, commercial or not-for-profit sectors.

Disclaimer The findings and conclusions in this report are those of the authors and do not necessarily represent the official position of the US Centers for Disease Control and Prevention, Sierra Leone Ministry of Health and Sanitation, or Columbia University.

Competing interests None declared.

Patient consent Not required.

Provenance and peer review Commissioned; internally peer reviewed.

Data sharing statement № additional data are available.

Open access This is an open access article distributed in accordance with the Creative Commons Attribution Non Commercial (CC BY-NC 4.0) license, which permits others to distribute, remix, adapt, build upon this work non-commercially, and license their derivative works on different terms, provided the original work is properly cited and the use is non-commercial. See: http://creativecommons.org/ licenses/by-nc/4.0/

(C) Article author(s) (or their employer(s) unless otherwise stated in the text of the article) 2018. All rights reserved. No commercial use is permitted unless otherwise expressly granted.

\section{REFERENCES}

1. WHO. WHO statement on end of Ebola flare-up in Sierra Leone. 2016. http://www.who.int/mediacentre/news/statements/2016/endflare-ebola-sierra-leone/en

2. Parliament UK. Ebola: responses to a public health emergency. 2016. https://publications.parliament.uk/pa/cm201516/cmselect/ cmintdev/338/33804.htm

3. Baize S, Pannetier D, Oestereich L, et al. Emergence of Zaire Ebola virus disease in Guinea. N Engl J Med 2014;371:1418-25.

4. Migliani R, Keïta S, Diallo B, et al. [Epidemiological aspects of Ebola virus disease in Guinea (december 2013-april 2016)]. Bull Soc Pathol Exot 2016;109:218-35.

5. Wauquier N, Bangura J, Moses L, et al. Understanding the emergence of ebola virus disease in sierra leone: stalking the virus in the threatening wake of emergence. PLoS Curr 2015;7.

6. WHO. Statement on the 1st meeting of the IHR Emergency Committee on the 2014 Ebola outbreak in West Africa. 2014. http:// www.who.int/mediacentre/news/statements/2014/ebola-20140808/ en

7. WHO. Statement on the 9th meeting of the IHR Emergency Committee regarding the Ebola outbreak in West Africa. 2016. http:// www.who.int/mediacentre/news/statements/2016/end-of-ebolapheic/en

8. WHO. Ebola situation report - 30 March 2016. 2016. http://apps. who.int/iris/bitstream/10665/204714/1/ebolasitrep_30mar2016_eng. pdf

9. Shultz JM, Cooper JL, Baingana F, et al. The role of fear-related behaviors in the 2013-2016 West Africa Ebola Virus Disease Outbreak. Curr Psychiatry Rep 2016;18:104.

10. Bali S, Stewart KA, Pate MA. Long shadow of fear in an epidemic: fearonomic effects of Ebola on the private sector in Nigeria. BMJ Glob Health 2016;1:e000111.

11. Karafillakis E, Jalloh MF, Nuriddin A, et al. 'Once there is life, there is hope' Ebola survivors' experiences, behaviours and attitudes in Sierra Leone, 2015. BMJ Glob Health 2016;1:e000108.

12. Kondé MK, Diop MK, Curtis MY, et al. Sex practices and awareness of Ebola virus disease among male survivors and their partners in Guinea. BMJ Glob Health 2017;2:e000412.

13. Rabelo I, Lee V, Fallah MP, et al. Psychological distress among ebola survivors discharged from an ebola treatment unit in Monrovia, Liberia - a qualitative study. Front Public Health 2016;4:142.

14. Mohammed A, Sheikh TL, Gidado S, et al. An evaluation of psychological distress and social support of survivors and contacts of Ebola virus disease infection and their relatives in Lagos, Nigeria: a cross sectional study-2014. BMC Public Health 2015; $15: 824$

15. Keita MM, Taverne B, Sy Savané S, et al. Depressive symptoms among survivors of Ebola virus disease in Conakry (Guinea) preliminary results of the PostEboGui cohort. BMC Psychiatry 2017;17:127.

16. Li L, Wan C, Ding R, et al. Mental distress among Liberian medical staff working at the China Ebola Treatment Unit: a cross sectional study. Health Qual Life Outcomes 2015;13:156.

17. Waterman S, Hunter ECM, Cole CL, et al. Training peers to treat Ebola centre workers with anxiety and depression in Sierra Leone. Int J Soc Psychiatry 2018;64:156-65.

18. Smith MW, Smith PW, Kratochvil CJ, et al. The psychosocial challenges of caring for patients with ebola virus disease. Health Secur 2017;15:104-9.

19. McMahon SA, Ho LS, Brown $\mathrm{H}$, et al. Healthcare providers on the frontlines: a qualitative investigation of the social and emotional impact of delivering health services during Sierra Leone's Ebola epidemic. Health Policy Plan 2016;31:1232-9.

20. Sipos ML, Kim PY, Thomas SJ, et al. U.S. service member deployment in response to the ebola crisis: the psychological perspective. Mil Med 2018;183:e171-e178.

21. Gershon R, Dernehl LA, Nwankwo E, et al. Experiences and psychosocial impact of West Africa Ebola Deployment on US Health Care Volunteers. PLoS Curr 2016;8.

22. Vyas KJ, Delaney EM, Webb-Murphy JA, et al. Psychological Impact of Deploying in Support of the U.S. Response to Ebola: a systematic review and meta-analysis of past outbreaks. Mil Med 2016;181:e151 5-e1531.

23. Jalloh MF, Li W, Bunnell RE, et al. Impact of Ebola experiences and risk perceptions on mental health in Sierra Leone, July 2015. BMJ Glob Health 2018;3:e000471.

24. Jalloh MF, Sengeh P, Monasch R, et al. National survey of Ebolarelated knowledge, attitudes and practices before the outbreak peak in Sierra Leone: August 2014. BMJ Glob Health 2017;2:e000285.

25. Jalloh MF, Robinson SJ, Corker J, et al. Knowledge, attitudes, and practices related to ebola virus disease at the end of a national epidemic - Guinea, August 2015. MMWR Morb Mortal Wkly Rep 2017;66:1109-15.

26. Deen GF, McDonald SLR, Marrinan JE, et al. Implementation of a study to examine the persistence of Ebola virus in the body fluids of Ebola virus disease survivors in Sierra Leone: Methodology and lessons learned. PLOS Negl Trop Dis 2017;11:e0005723.

27. Deen GF, Broutet N, Xu W, et al. Ebola RNA persistence in semen of ebola virus disease survivors - final report. N Engl J Med 2017;377:1428-37.

28. Eggo RM, Watson $\mathrm{CH}$, Camacho A, et al. Duration of Ebola virus RNA persistence in semen of survivors: population-level estimates and projections. Euro Surveill 2015;20:30083.

29. Thorson A, Formenty P, Lofthouse C, et al. Systematic review of the literature on viral persistence and sexual transmission from recovered Ebola survivors: evidence and recommendations. $B M J$ Open 2016;6:e008859.

30. Diallo B, Sissoko D, Loman NJ, et al. Resurgence of Ebola virus disease in guinea linked to a survivor with virus persistence in seminal fluid for more than 500 days. Clin Infect Dis 2016;63:1353-6.

31. Sow S, Desclaux A, Taverne B, et al. [Ebola in Guinea: experience of stigma among health professional survivors]. Bull Soc Pathol Exot 2016:109:309-13.

32. Kim HS, Sherman DK, Updegraff JA. Fear of Ebola: the influence of collectivism on xenophobic threat responses. Psychol Sci 2016;27:935-44.

33. Prati G, Pietrantoni L. Knowledge, risk perceptions, and xenophobic attitudes: evidence from italy during the ebola outbreak. Risk Anal 2016;36:2000-10.

34. Lawrence P, Danet N, Reynard O, et al. Human transmission of Ebola virus. Curr Opin Virol 2017;22:51-8.

35. Jalloh MF, Bunnell R, Robinson S, et al. Assessments of Ebola knowledge, attitudes and practices in Forécariah, Guinea and Kambia, Sierra Leone, July-August 2015. Philos Trans R Soc Lond B Biol Sci 2017;372.

36. Alpren C, Jalloh MF, Kaiser R, et al. The 117 call alert system in Sierra Leone: from rapid Ebola notification to routine death reporting BMJ Glob Health 2017;2:e000392.

37. Betancourt TS, Khan KT. The mental health of children affected by armed conflict: protective processes and pathways to resilience. Int Rev Psychiatry 2008:20:317-28.

38. Giorgi G, Fiz Perez FS, Castiello D'Antonio A, et al. Psychometric properties of the Impact of Event Scale- 6 in a sample of victims of bank robbery. Psychol Res Behav Manag 2015;8:99-104. 
39. Reardon S. Ebola's mental-health wounds linger in Africa. Nature 2015;519:13-14.

40. Shultz JM, Baingana F, Neria Y. The 2014 Ebola outbreak and mental health: current status and recommended response. JAMA 2015;313:567-8

41. Kessler RC, Sonnega A, Bromet E, et al. Posttraumatic stress disorder in the National Comorbidity Survey. Arch Gen Psychiatry 1995;52:1048-60.

42. Bromet E, Sonnega A, Kessler RC. Risk factors for DSMIII-R posttraumatic stress disorder: findings from the National Comorbidity Survey. Am J Epidemiol 1998;147:353-61.

43. Betancourt TS, Brennan RT, Vinck P, et al. Associations between mental health and ebola-related health behaviors: a regionally representative cross-sectional survey in post-conflict Sierra Leone. PLoS Med 2016;13:e1002073.

44. Betancourt TS, Borisova II, Williams TP, et al. Sierra Leone's former child soldiers: a follow-up study of psychosocial adjustment and community reintegration. Child Dev 2010;81:1077-95.

45. Betancourt TS, McBain R, Newnham EA, et al. Context matters: community characteristics and mental health among war-affected youth in Sierra Leone. J Child Psychol Psychiatry 2014;55:217-26.
46. Betancourt TS, Newnham EA, McBain R, et al. Post-traumatic stress symptoms among former child soldiers in Sierra Leone: follow-up study. Br J Psychiatry 2013;203:196-202.

47. Pennebaker JW, Beall SK. Confronting a traumatic event: toward an understanding of inhibition and disease. J Abnorm Psychol 1986;95:274-81.

48. Pennebaker JW. The social, linguistic, and health consequences of emotional disclosure. Wiley, 2009.

49. Espinola M, Shultz JM, Espinel Z, et al. Fear-related behaviors in situations of mass threat. Disaster Health 2016;3:102-11.

50. Kroenke K, Spitzer RL, Williams JB, et al. An ultra-brief screening scale for anxiety and depression: the PHQ-4. Psychosomatics 2009;50:613-21.

51. Löwe B, Wahl I, Rose M, et al. A 4-item measure of depression and anxiety: validation and standardization of the Patient Health Questionnaire-4 (PHQ-4) in the general population. J Affect Disord 2010;122:86-95.

52. Thoresen S, Tambs K, Hussain A, et al. Brief measure of posttraumatic stress reactions: impact of Event Scale-6. Soc Psychiatry Psychiatr Epidemiol 2010;45:405-12. 